\title{
Seasonal Variation in Seed Dispersal by Tamarins Alters Seed Rain in a Secondary Rain Forest
}

\author{
Laurence Culot • Fernando Julio João Muñoz Lazo • Marie-Claude Huynen • \\ Pascal Poncin • Eckhard W. Heymann
}

Received: 18 July 2009 / Accepted: 21 November 2009 /

Published online: 15 May 2010

C The Author(s) 2010. This article is published with open access at Springerlink.com

\begin{abstract}
Reduced dispersal of large seeds into degraded areas is one of the major factors limiting rain forest regeneration, as many seed dispersers capable of transporting large seeds avoid these sites with a limited forest cover. However, the small size of tamarins allows them to use small trees, and hence to disperse seeds into young secondary forests. Seasonal variations in diet and home range use might modify their contribution to forest regeneration through an impact on the seed rain. For a 2-yr period, we followed a mixed-species group of tamarins in Peru to determine how their role as seed dispersers in a 9-yr-old secondary-growth forest varied across seasons. These tamarins dispersed small to large seeds of 166 tree species, 63 of which were into a degraded area. Tamarins' efficiency in dispersing seeds from primary to secondary forest varied across seasons. During the late wet season, high dietary diversity and long forays in secondary forest allowed them to disperse large seeds involved in later stages of regeneration. This occurred precisely when tamarins spent a more equal amount of time eating a high diversity of fruit species in primary forest and pioneer species in secondary forest. We hypothesized that well-balanced fruit availability induced the movement of seed dispersers between these 2 habitats. The noteworthy number of large-seeded plant species dispersed by such small primates suggests that tamarins play an important, but previously neglected, role in the regeneration and maintenance of forest structure.
\end{abstract}

Electronic supplementary material The online version of this article (doi:10.1007/s10764-010-9413-7) contains supplementary material, which is available to authorized users.

L. Culot $(\bowtie) \cdot$ M.-C. Huynen $\cdot$ P. Poncin

Behavioral Biology Unit, University of Liège, 4020 Liège, Belgium

e-mail: Laurence.Culot@ulg.ac.be

E. W. Heymann

Department of Behavioral Ecology and Sociobiology, German Primate Center of Goettingen,

37077 Goettingen, Germany

\section{F. J. J. Muñoz Lazo}

Department of Ecology and Fauna, National University of Peruvian Amazon, Iquitos, Loreto, Perú 
Keywords forest regeneration $\cdot$ Peru $\cdot$ Saguinus $\cdot$ seasonality $\cdot$ seed dispersal

\section{Introduction}

The presence of animal seed dispersers is necessary for the maintenance of local plant species richness and plays a key role in the regeneration of degraded areas (Webb and Peart 2001). Habitat fragmentation threatens biodiversity by isolating the remaining habitat, therefore limiting the movement of biota and altering processes in previously connected landscapes. Usually quickly abandoned when productivity declines (Uhl et al. 1988), pastures and plantations slowly regenerate into secondary forest, a process that can take 65-4000 yr (Liebsch et al. 2008; Martínez-Garza and Howe 2003). The early successional stages strongly depend on abiotic dispersal and on bat and bird dispersal of the small seeds of pioneer species, initiating tree colonization (Da Silva et al. 1996; Gorchov et al. 1993; Medellín and Gaona 1999). Once this early recolonization has succeeded, subsequent succession can be assured through further seed dispersal by birds and bats and the attraction of additional seed dispersers like small arboreal mammals (Gorchov et al. 1993). That few large seeds are dispersed during the first stages of the succession is the main factor slowing the recovery of tropical rain forests (Holl 1999; Hooper et al. 2005; Parrotta et al. 1997). Indeed, many mammalian frugivores avoid more open or young degraded areas, lacking suitable substrates for locomotion and with potential higher predation risk (Chapman and Chapman 1999). In the Neotropics, many primate species enter 30- or 50-yr-old secondary forests (Vulinec et al. 2006). However, very few visit younger degraded areas (Parrotta et al. 1997), which explains the poor understanding of their role in forest regeneration compared to bats and birds.

Primates constitute $25-40 \%$ of the frugivore biomass in tropical forests and are assumed to play an important role as seed dispersers (Chapman 1995). This is particularly important for the regeneration of disturbed areas, but, if true, necessitates that dispersers prosper in disturbed habitats. According to Johns and Skorupa (1987), small primate species, such as the partially frugivorous tamarins (Saguinus), which are able to feed on early-colonizing fruit species, are likely to survive in degraded habitats. Callitrichid species are considered important agents in the seed dispersal cycle but still their role is poorly known. In contexts where medium- and large-sized mammals have become rare (Stoner et al. 2007), the appraisal of small primate species role becomes increasingly crucial. In addition, despite their small body size, Saguinus handle and disperse seeds as large as $2.35 \mathrm{~cm}$ (Knogge and Heymann 2003), and because they can disperse intact seeds from primary to secondary forest (Oliveira and Ferrari 2000), their ultimate role in forest regeneration may be vital in the absence of larger primates that have succumbed to habitat loss and over-hunting.

As habitat utilization by primate groups is closely related to food abundance (Olupot et al. 1997), the composition, structure, and phenology of the plant community in regenerating areas will strongly affect the movements of these seed dispersers. Seasonal variations in fruit availability affect primary consumers, which respond not only by seasonal breeding or migration but also by dietary switching 
and alterations in range use (Hemingway and Bynum 2005; Van Schaik et al. 1993). In the case of seed dispersers, these last 2 specific adaptations can influence the intensity of seed dispersal, as well as the composition and spatial structure of the seed rain (Chapman and Russo 2006), thus affecting the future template of recruitment.

Following Russo et al. (2006), who suggest that knowing the behavior of seed dispersers helps us to understand the seed shadow better, we aimed to evaluate the seasonal variations of feeding and ranging behaviors of a mixed-species group of tamarins (mustached, Saguinus mystax Spix, and saddle-back tamarins, Saguinus fuscicollis Spix), and the consequences of these behaviors on primary seed dispersal in a pasture abandoned for nine years which is now a regenerating secondary forest. We addressed a set of specific questions to know whether the possible seasonal variations of seed rain in the secondary forest were linked to the relative time tamarins spent feeding on fruits in the primary and secondary forests. As late successional species typically present in the primary forest usually produce medium and large seeds while pioneer species covering the largest part of the secondary forest in our study site produce small seeds (Foster and Janson 1985), throughout the article we refer to small vs. medium/large seeds by using the pioneer vs. nonpioneer species dichotomy.

1) Seasonality and home range use: We evaluated how season affected the use of secondary forest (frequency of entries, percentage of time spent there, mean duration of entries, and distance traveled). We predicted higher frequencies and longer durations of entries into secondary forest during the dry season, a period of low fruit availability in primary forest (Garber 1993).

2) Seasonality and diet: We evaluated how season affected the diet (dietary diversity, percentage of pioneer species eaten) and feeding behavior of tamarins (time spent eating fruits in both habitats). As secondary forest is dominated by pioneer plant species, we evaluated how the relative time dedicated by tamarins to feed on fruits in both habitats affected tamarins' diet. We expected a lower dietary diversity and a larger proportion of pioneer species in tamarins' diet during the dry season, a period during which we expected that tamarins would spend more time feeding on fruits in secondary forest and less time in primary forest.

3) Tamarins as seed dispersers: We determined the quality of tamarins as seed dispersers in terms of amount of seed species eaten, seed size, and seed shadow. We investigated whether seed density decreased with distance from a forest edge or whether it was concentrated around feeding trees in secondary forest. Assuming that tamarins enter secondary forest to feed on fruits, we predicted a higher seed density around feeding trees.

4) Seasonality and seed rain in secondary forest: We evaluated whether or not tamarins dispersed nonpioneer seeds from primary to secondary forest during the entire year, and whether the observed patterns reflected the diet, the feeding behavior, and/or the use of secondary forest by tamarins. We predicted that a higher quantity of seeds, but essentially of pioneer species, would be dispersed in secondary forest, when the relative time spent by tamarins feeding on fruits in secondary forest compared to primary forest is the highest. 


\section{Methods}

\section{Study Area}

We collected field data during four 6-mo periods, with each month represented twice: September 2005-February 2006, June-November 2006, March-August 2007, and December 20070-May 2008. The study took place at the Estación Biológica Quebrada Blanco (EBQB) located in northeastern Peru $\left(04^{\circ} 21^{\prime} \mathrm{S}, 73^{\circ} 09^{\prime} \mathrm{W}\right)$ on the right bank of the Quebrada Blanco, an affluent of the Río Tahuayo. Primary forest dominates the 100-ha study area that is surrounded by primary and secondary forests. The southern part of the study site includes a 3.5-ha portion of a previous pasture (15 ha), most of which was abandoned and left to regenerate $9 \mathrm{yr}$ before the end of the study (Fig. 1). The original primary forest was cut and burned in 1984 to grow bananas (Musa sp), yuccas (Manihot esculenta Crantz), and uvillas (Pourouma cecropiifolia Mart.). Trees of pijuayo-palmito (Bactris gasipaes Kunth) and aguaje (Mauritia flexuosa L.f.) were also planted during this period and were still present when the pasture was abandoned. After 1990, this area was regularly used to graze 8 buffalos until 1999, and less frequently until 2001. This area has now low plant diversity and is dominated by herbs, shrubs, and small trees, most of them $<5 \mathrm{~m}$ in height and of species typical of secondary forest (Zárate, pers. comm.). Annual rainfall, measured at the nearest meteorological station (Tamshiyacu, $c a .40 \mathrm{~km}$ northwest of the EBQB) reached $2958 \mathrm{~mm}$ in 2006. During the study period, the monthly minimum and maximum temperatures averaged $18.8^{\circ} \mathrm{C}$ and $30.2^{\circ} \mathrm{C}$ and patterns of rainfall were very close to those described by Garber (1993) with a short dry season from July to September, an early wet season with increasing rainfall from October to January, a main wet season from February to May, and a late wet season with decreasing rainfall in June.

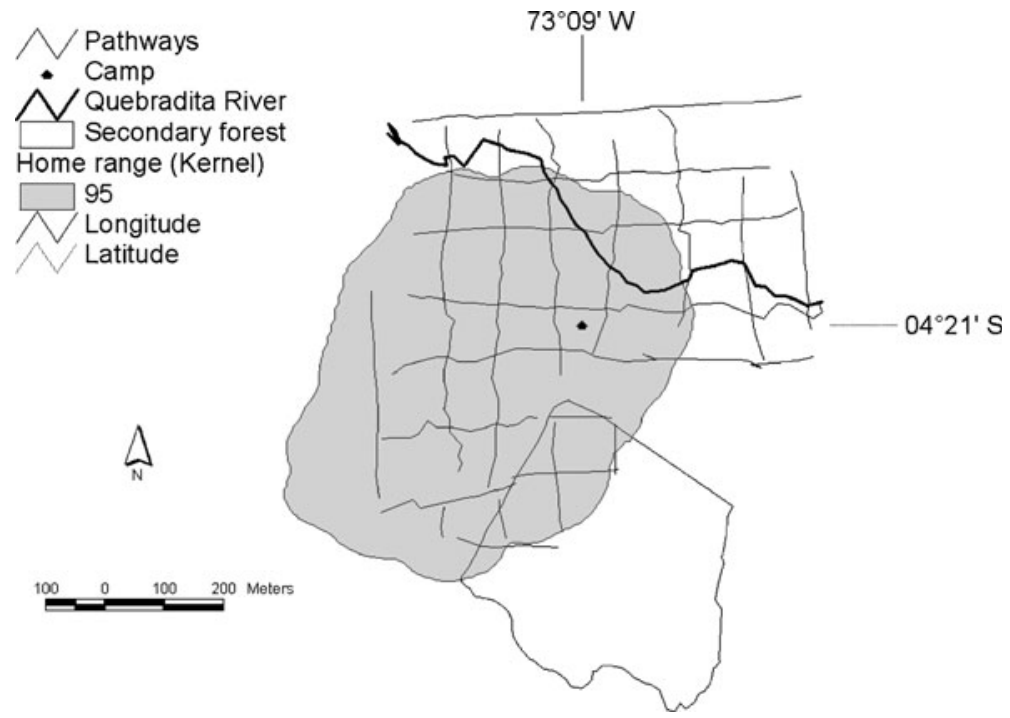

Fig. 1 Map of the study site showing the home range of Saguinus fuscicollis and Saguinus mystax with the Kernel method. The Kernel core shows the area with $95 \%$ of probability of finding the monkeys. The area includes a portion of 3.5-ha secondary forest in the south. 
Behavioral and Ecological Data

We studied a mixed-species group of 7-15 tamarins including 4-10 Saguinus mystax (380-650 g; Soini and Soini 1982), and 3-6 Saguinus fuscicollis (240-440 g; Soini and Coppula 1981). We followed the tamarins for $4 \mathrm{~d} / \mathrm{wk}, 3-4 \mathrm{wk} / \mathrm{mo}$, from early morning when they left their sleeping sites until late afternoon when they entered a sleeping tree, which resulted in a total of $2303 \mathrm{~h}$ of observation.

Feeding Behavior Every $10 \mathrm{~min}$, we registered the behavior of each visible tamarin of the group as moving, resting, social activity, vigilance, agonistic interaction, eating gum, foraging/eating insects, and eating fruits (EF) with the scan sampling method (Martin and Bateson 1993) and specifying the habitat in which we observed the behavior. We used only the "eating fruits" behavior in the analyses. As Saguinus fuscicollis and Saguinus mystax exhibit highly coordinated feeding and ranging patterns (Garber 1988), we could record all feeding bouts (defined as the period when one or several group members were feeding in a fruiting plant) for both species with the all-occurrence method (Martin and Bateson 1993). For every feeding bout, we registered the tamarin species present, the time of entry into the fruiting plant, the GPS coordinates, the plant life form (tree, vine, [hemi]epiphyte), and the plant species. We collected leaves, fruits, and seeds of every new plant species for identification and establishment of a reference seed collection. We also took data such as tree circumference at breast height $(\mathrm{CBH})$, height, and presence/absence of exudates. We marked every plant used for food with a numbered metal tag.

These species of tamarins spent most of their time in association (Heymann 1990) and fed almost entirely on the same fruit species (Sorensen' $s$ Index $=0.81$ for this study). Therefore, we calculated the monthly percentage of feeding bouts on every fruit species for Saguinus mystax and Saguinus fuscicollis together as our goal was to determine the overall effect of the mixed-species group on forest regeneration. On a monthly basis, we calculated the percentage of feeding bouts on pioneer species and dietary diversity via the Shannon index. Finally, we also determined on a monthly basis the relative time they dedicated to feed on fruits in both habitats expressed by as secondary-forest-to-primary-forest ratio (EF pf/EF sp; number of "eating fruits" scans in secondary forest/number of "eating fruits" scans in primary forest).

Ranging Patterns We mapped the GPS coordinates of the location of the tamarin group every $20 \mathrm{~min}$. We also tracked the route used by tamarins in the secondary forest and calculated the time they spent in the secondary forest by noting the moment the first group member entered and the moment the last one left.

We analyzed geospatial data using Arcview 3.3. We estimated the home range of the study group using the Kernel method to delimitate the area with $95 \%$ of probability to find the monkeys (Kernel 95\%; Rodgers and Carr 1998). In addition, we delimitated the area used by the mixed-species group during each season, using multiple Kernel cores showing the zones of highest (Kernel 50\%), medium (75\%), and lowest (95\%) intensity of use. We calculated the distances traveled by tamarins in the secondary forest from tracks obtained with the GPS to reach a more accurate estimate, as short entries could be missed by using only waypoints taken at 20-min intervals. We calculated, on a weekly basis, the frequency of entries in the secondary 
forest (number of entries/number of observation days). To correlate data of ranging and feeding behavior, we calculated, on a monthly basis, the frequency and mean duration of entries ( $\Sigma$ duration of entries/number of entries), the percentage of time spent in secondary forest, and the mean distance traveled for each entry.

Primary Seed Dispersal With a GPS, we took a waypoint for every observed dispersal event (a tamarin defecation containing $\geq 1$ seed) and counted and identified the seeds in situ. Reliable species identification was made possible from the knowledge of what they had eaten previously. In addition, we built a seed collection and checked repeatedly the seed fate later as part of another project, which allowed an eventual correction of the initial identification. The seed collection allowed us to determine the mean length and width for every seed species. We considered seeds $>1 \mathrm{~cm}$ in length as large. As it was difficult to see and to identify very small-seeded species $(<2 \mathrm{~mm})$, we certainly underestimated the number of small seed species dispersed. We considered a group of small seeds belonging to a single species in a fecal pellet as 1 seed in the analysis because it was impossible to determine precisely the quantity of seeds per defecation. We calculated the relative percentage of seeds dispersed in secondary forest vs. primary forest, and derived the proportion allocated to pioneer vs. nonpioneer seed species. We considered seeds as from a pioneer species when they were $<5 \mathrm{~mm}$ (Foster and Janson 1985) and when adult specimens of the species were present in the secondary forest. We estimated the density of seeds dispersed in both types of forest by dividing the number of seeds dispersed by the size of the respective area. In the secondary forest, we delimited successive strips of $10 \mathrm{~m}$ width along the edge to correlate the density of seeds dispersed with the distance from the forest edge (from primary forest to secondary forest).

\section{Statistical Analyses}

We performed all statistical analyses via Statistica 8 with $\alpha=0.05$. We used nonparametric tests if variables did not conform to conditions of normality and homoscedasticity after transformation, or if $n<30$ (for analysis of variance).

We tested the effect of season (predictor) on all the variables of ranging and feeding behaviors and of primary seed dispersal (responses) using the nonparametric Kruskal-Wallis test. The Kruskal-Wallis multiple comparison tests performed by Statistica give the adjusted $p$-value directly. We tested the relation between the relative time dedicated eating fruits in both habitats (EF sf/EF pf) and dietary diversity and diet composition using Pearson correlation (noted as $r$ ). We tested the relation between seed dispersal variables and ranging and feeding variables using Pearson correlation except for the percentage of pioneer species seeds dispersed for which we used a Spearman correlation (noted as $r_{S}$ ). We used the square-root transformation of the percentage of feeding bouts on pioneer species, the percentage of time per day in secondary forest, the relative time eating fruits in both habitats (EF sf/EF pf), and the percentage of total seeds and nonpioneer seeds dispersed for the Pearson correlations. We used simple regressions to explore the relation between seed density (dependent variables) and distance from the forest edge (predictor) while we used a Pearson correlation to test the relationship between seed density and feeding tree density. Then, we did a partial correlation between seed density and 
feeding tree density in secondary forest using distance as cofactor. Finally, we used a polynomial regression to test the effect of the frequency of entries on the mean duration of entries in secondary forest and the effect of the relative time eating fruits in both habitats (EF sf/EF pf) on the frequency of entries in secondary forest.

\section{Results}

\section{Seasonality and Home Range Use}

We estimated the home range of the mixed-species group of tamarins at 34.1 ha (Fig. 1) of which $10.3 \%$ was secondary forest (Fig. 1). Tamarins varied the use of their home range across seasons (Fig. 2). The areas most intensively used by tamarins were almost exclusively located in the secondary forest during the dry season, in primary and secondary forest during the late wet season, and almost exclusively in the primary forest during the early and main wet seasons (Fig. 2). Season affected significantly the frequency of entries into secondary forest $\left(\mathrm{H}_{3,73}=\right.$ $13.59, p=0.003$ ) with more frequent entries in the dry season than in the main (adjusted $p=0.008$ ) and early wet seasons (adjusted $p=0.01$ ). The mean duration of entries $\left(H_{3,172}=12.34, p=0.006\right)$ and distances traveled $\left(H_{3,141}=10.08, p=0.02\right)$ varied significantly with season too, while the percentage of time spent in secondary forest only approached significance $\left(H_{3,24}=7.25, p=0.06\right)$. The duration of entries

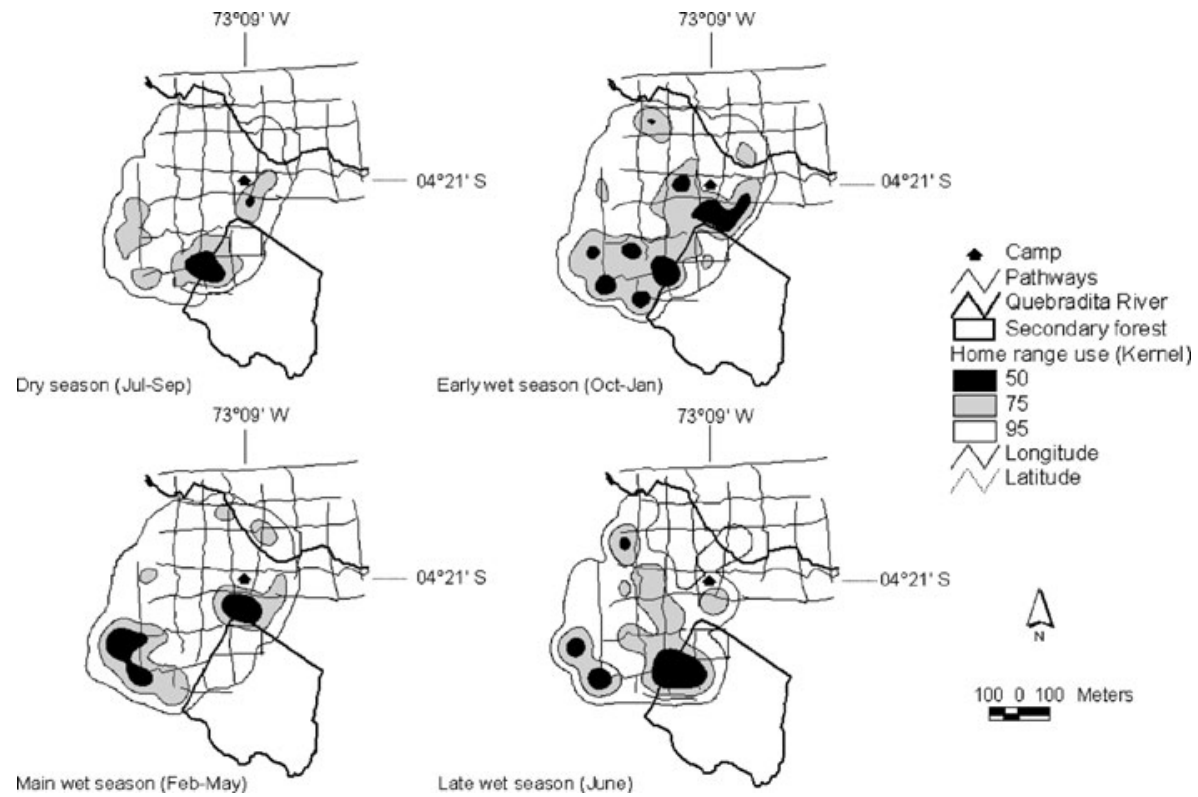

Fig. 2 Home range use by a mixed-species group of tamarins, Saguinus fuscicollis and Saguinus mystax, across seasons. The Kernel cores were built from the waypoints taken during group follows. Black indicates the area of highest intensity of use (50\% of probability of finding the monkeys), gray indicates the area of medium intensity of use (75\%), and white indicates the area of lowest intensity of use (95\%). 
was significantly longer in the late wet season (median duration: $89 \mathrm{~min}$ ) than in the early (adjusted $p=0.02$ ) and the main wet season (adjusted $p=0.03$ ), 51 and $49 \mathrm{~min}$ respectively, while distances traveled within secondary forest were longer in the late wet (median distance: $410 \mathrm{~m})$ than in the early wet $(211 \mathrm{~m})$ season (adjusted $p=0.01)$.

\section{Seasonality and Diet}

During the study period, the mixed-species group of tamarins consumed 307 fruit species (251 by Saguinus fuscicollis and 267 by Saguinus mystax) including 216 trees $(70.3 \%), 73$ vines $(23.8 \%), 14$ (hemi)epiphytes $(4.7 \%)$, and 4 palms $(1.3 \%)$ (see electronic supplement S1). The composition and diversity of the diet varied considerably across months and seasons (see electronic supplement S2). During the dry and early wet seasons, a large part of the diet consisted of pioneer species such as Cecropia sciadophylla Mart., Cecropia distachya Huber, or Bellucia pentamera Naudin (see electronic supplement S2). The percentage of feeding bouts on pioneer species varied significantly between seasons $\left(H_{3,24}=13.99, p=0.002\right)$ : tamarins consumed fewer pioneer species during the main wet season than during the early wet (adjusted $p=0.003$ ) and dry seasons (adjusted $p=0.03$ ). Likewise, season significantly influenced the dietary diversity measured by the Shannon index $\left(H_{3,24}=8.11, p=0.04\right)$ : dietary diversity was significantly lower in the early wet season than in the main wet season (adjusted $p=0.04$ ). In contrast, season did not influence the relative time spent eating fruits in both habitats $\left(H_{3,24}=3.98, p=0.173\right)$. An increase of secondary-to-primary-forest ratio of time spent eating fruits provoked a decrease of dietary diversity $(n=24, r=-0.46, p=0.025)$ and an increase of the proportion of feeding bouts on pioneer species $(n=24, r=-0.70, p<0.001)$.

\section{Tamarins as Seed Dispersers in Secondary Forest}

The mixed-species group of tamarins dispersed the seeds of $54.1 \%$ of the species consumed (166/307), including 118 trees, 40 vines, 7 (hemi)epiphytes, and 1 palm species (see electronic supplement S1). Saguinus mystax dispersed 151 species (56.6\% of species consumed), while Saguinus fuscicollis dispersed 154 species (61.4\% of species consumed). Dispersed seed density was higher in primary forest (70.8 seeds $\mathrm{ha}^{-1}$ ) than in secondary forest $\left(60.2\right.$ seeds ha $\left.{ }^{-1}\right)$. About $8.7 \%$ of seeds (250/2860) belonging to 63 species were dispersed into secondary forest where tamarins spent $8.4 \%$ of their time. Among the seeds dispersed in secondary forest, $51.2 \%$ belonged to species present only in the primary forest. All the seeds dispersed in the secondary forest were relatively large, with $57.6 \%$ of seeds $>1 \mathrm{~cm}$ (see Fig. 3 for seed length and width distribution). Cecropiaceae (Cecropia and Pourouma), Fabaceae (Inga and Parkia), and Moraceae (Naucleopsis, Ficus, Helicostylis, and Clarisia) were the families most often dispersed into secondary forest. Byrsonima poeppigiana A.Juss. was the species dispersed in the greatest number and which seeds were dispersed during the main wet season (B. poeppigiana seeds are quite small). Dicranostyles scandens Benth., Paullinia sp. 4, and Parkia panurensis Benth. ex H. C. Hopkins. were the nonpioneer seed species most frequently represented in secondary forest (in terms of dispersal events and number of seeds, and excluding Byrsonima poeppigiana) and were dispersed during the dry and late 


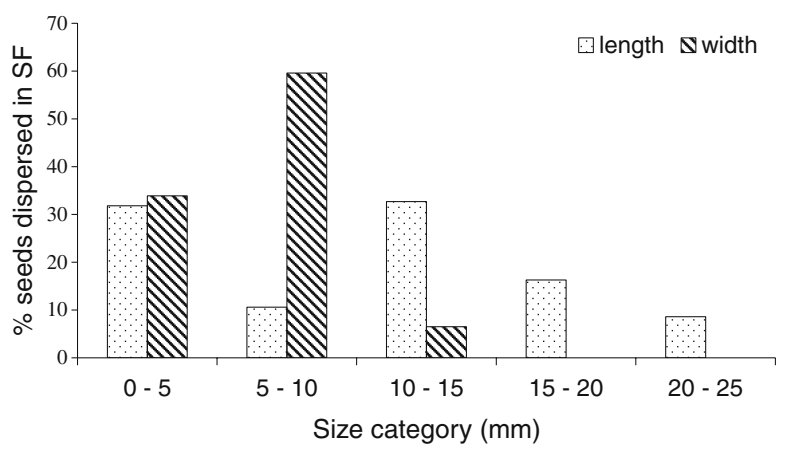

Fig. 3 Percentage of seeds dispersed in secondary forest (SF) for different seed size categories (length and width).

wet seasons. Seed density decreased with distance from the edge in secondary forest $\left(n=14, r^{2}=0.37, F_{1,12}=7.06, \beta=-0.61, p=0.02\right.$; Fig. 4) while it increased with feeding tree density $\left(n=14, r=0.71, r^{2}=0.50, p=0.005\right)$. When controlling for the distance variable, seed density significantly correlated with feeding tree density $(n=$ $\left.14, r=0.55, r^{2}=0.31, p=0.049\right)$, which indicated a concentration of seeds dispersed around pioneer feeding patches. Indeed, increased seed density between 60 and $100 \mathrm{~m}$ from the forest edge corresponded to several patches of Cecropia and Bellucia pentamera trees, whereas 74.4\% (186/250) of the seeds dispersed in secondary forest were from other plant species.

\section{Seasonality and Seed Rain in Secondary Forest}

The quantity and species composition of the seeds dispersed in secondary forest varied during the year, as the percentage of pioneer species seeds changed significantly with seasons $\left(H_{3,18}=12.19, p=0.006\right.$; Fig. 5), with a lower percentage in the main wet season than in the early wet season (adjusted $p=0.017$ ) and in the

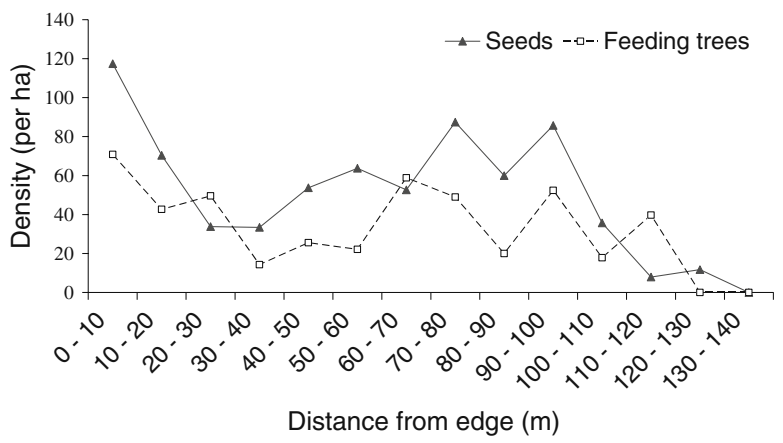

Fig. 4 Changes in seed density and feeding tree density expressed as the number of seeds and feeding trees per hectare in secondary forest with distance from edge. Seed density and feeding tree density are based on the number of seeds or trees in the successive strips of $10 \mathrm{~m}$ width along the edge. We considered the area of secondary forest comprising 0-140 m from the edge which corresponds to the area where seeds were dispersed. 


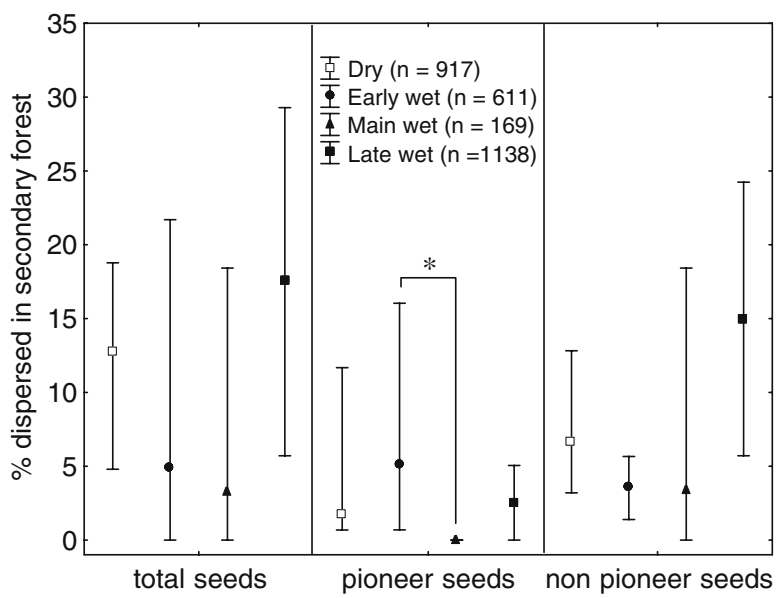

Fig. 5 Median percentage of total seeds, pioneer seeds and nonpioneer seeds dispersed in secondary forest (vertical bars represent the minimum and maximum \%) according to season. Significant differences resulting from the Kruskal-Wallis post hoc tests are shown with an asterisk $(p<0.05)$.

dry season, although the difference was not statistically significant (adjusted $p=$ 0.07). In contrast, the percentage of nonpioneer species seeds dispersed was higher in secondary forest during the late wet season, although again the difference was not statistically significant $\left(H_{3,18}=4.87, p=0.18\right.$; Fig. 5). The percentage of seeds dispersed in secondary forest correlated positively with all the variables but dietary diversity (Table I), whereas the percentage of pioneer species seeds dispersed was correlated negatively with the dietary diversity and positively with all the other variables but the mean distance traveled in secondary forest. The nonpioneer species seeds dispersed correlated only with the percentage of time tamarins spent in the secondary forest, the mean duration of their entries, and the mean distance traveled

Table I Results of Pearson and Spearman correlations between seed dispersal variables and feeding and ranging variables in secondary forest $(\mathrm{SF})$

\begin{tabular}{|c|c|c|c|c|c|c|}
\hline & \multicolumn{2}{|c|}{$\begin{array}{l}\text { Square root } \% \\
\text { total seeds }\end{array}$} & \multicolumn{2}{|c|}{$\begin{array}{l}\text { Square root } \% \\
\text { non pioneer seeds }\end{array}$} & \multicolumn{2}{|c|}{$\%$ pioneer seeds } \\
\hline & $r$ & $p$ & $r$ & $P$ & $r_{S}$ & $p$ \\
\hline EF sf/ EF pf & 0.630 & 0.005 & 0.349 & 0.156 & 0.708 & 0.001 \\
\hline Dietary diversity & -0.438 & 0.069 & -0.045 & 0.859 & -0.743 & $<0.001$ \\
\hline Square root $\%$ feeding bouts on pioneer species & 0.598 & 0.009 & 0.225 & 0.369 & 0.885 & $<0.001$ \\
\hline Square root $\%$ time in $\mathrm{SF}$ & 0.777 & $<0.001$ & 0.580 & 0.012 & 0.647 & 0.004 \\
\hline Mean duration of entries & 0.784 & $<0.001$ & 0.727 & 0.001 & 0.622 & 0.006 \\
\hline Frequency & 0.628 & 0.005 & 0.368 & 0.132 & 0.681 & 0.002 \\
\hline Mean distance traveled in SF & 0.510 & 0.031 & 0.516 & 0.028 & 0.315 & 0.204 \\
\hline
\end{tabular}

Significant results are set in bold type. 
(Table I). The relation between the percentage of nonpioneer species seeds and the mean duration of entries in secondary forest was the strongest and showed that a higher proportion of non pioneer species seeds were dispersed in secondary forest by tamarins when the mean duration of their entries increased (Fig. 6a). Interestingly, the mean duration of entries in secondary forest was the highest when the frequency of these entries was intermediate $\left(n=24, r^{2}=0.50, F_{3,20}=6.81, p=0.002\right.$, Fig. 6b). These intermediate frequencies corresponded to medium values of EF sf/EF $\mathrm{pf}(n=24$, $r^{2}=0.81, F_{3,20}=27.92, p<0.000001$; Fig. 6c).

\section{Discussion}

Tamarins dispersed a high number of nonpioneer species seeds in the secondary forest. The dispersed seeds were in particularly high density around patches of pioneer feeding trees. The quantity and the species composition of seeds dispersed in secondary forest varied across seasons. A higher proportion of nonpioneer species seeds were dispersed during the late wet season when the duration of entries and the distance traveled in secondary forest were the greatest. Our results indicate that the seeds of species fruiting during the late wet season are more likely to be dispersed by tamarins in secondary forest, and hence to have the potential to contribute to the regeneration process.

\section{Seasonality and Home Range Use}

In our study, tamarins increased the frequency of their visits in secondary forest during the dry season, a period of low food abundance in primary forest for these monkeys in that region (Garber 1993). Similarly, it has been shown that howler monkeys and golden-handed tamarins avoid parts of their home range where $75 \%$ of the ripe fruits had been experimentally removed to simulate excessive human harvesting (Moegenburg and Levey 2003). Other animals, such as birds, enter abandoned pastures more frequently during the peak of fruit production in these habitats (Da Silva et al. 1996; Wunderle 1997), which might be the case in our study site as Cecropia sciadophylla, an important fruit resource in secondary forest for the study group, shows fruiting peak during the dry season (pers. obs.). The areas of highest intensity of use were essentially located in secondary forest during the dry season while they were located both in primary and secondary forest during the late wet season. During that period, tamarins did not enter secondary forest as often as during the dry season but each entry lasted longer and they traveled a greater distance. We hypothesized that the availability of fruits or preferred food was better balanced between the 2 habitats in late wet season than during the dry season. Therefore, tamarins did not need to expend as much effort by frequent entries into secondary forest as during the dry season. They may use incursions into secondary forest to check future fruit resource while opportunistically feeding on pioneer species. Moreover, the cloudier weather of the late wet season might allow tamarins to spend a fairly long time in a more open area while the sunny climate of the dry season might prompt them to return frequently to the primary forest to thermoregulate (Hill 2005). 


\section{Seasonality and Diet}

Seasonality in relative availability of fruits affected not only the tamarins' use of secondary forest but also their diet. Of all the behaviors that mitigate the impact of food scarcity, dietary switching appears to be the most important (van Schaik et al. 1993). Indeed, fruits from pioneer species located in secondary forest accounted for a large part of tamarins' diet in the dry season and the time tamarins spent eating fruits in secondary forest was directly related to a decrease of dietary diversity. Cecropia sp. was prominent in sustaining the mixed-species group during periods of fruit scarcity (Garber 1993), leading us to hypothesize that this resource was a fallback food, according to the definition of Furuichi et al. (2001). However, we lack the information necessary to discard the hypothesis of a preferred food resource. Peres (1993) reported that tamarins shifted to gum in periods of fruit scarcity. Similarly, Smith (2000) reported a shift to gum in August-November 1995 in EBQB but his study took place before the pasture was abandoned. Our results rather suggest that Cecropia fruiting in the secondary forest at our study site may have partially replaced gum during this dietary shift, as we did not observe a significant change in gum consumption across months (Culot, unpubl. data). Increasing regeneration on abandoned land over the last years increased the frequency of the tamarins' visits (Culot, unpubl. data), which in turn affected their dietary shifts during the dry season. Different habitats might thus cause different responses to fruit scarcity with significant consequences for seed dispersal.

\section{Tamarins as Seed Dispersers}

Saguinus fuscicollis and Saguinus mystax disperse a surprisingly high number of seed species in primary and secondary forest, which is consistent with their extreme dietary flexibility (Garber 1993) and the high plant diversity in the Loreto region (Ruokolainen and Tuomisto 1998). We reported a number of species consumed and dispersed almost twice as high as previously reported for the same study site by Knogge and Heymann (2003). This important difference is partly due to the longer time span of our study and to the distribution of our study periods over different seasons and years, which allows us to record species that do not set fruits each year. Of the $>300$ tree species $\geq 10 \mathrm{~cm} \mathrm{DBH}$ that have been reported in a 1-ha plot in the Loreto region (all plants considered, Gentry 1988), tamarins disperse the seeds of almost $40 \%$ (118 tree species). The low body mass of tamarins allows them to have access to a large range of plants of different size and life forms and to use relatively small and young trees present in the early stages of regeneration of the secondary forests. This characteristic may explain the noteworthy number of species dispersed, one of the highest ever recorded, and certainly the highest for a primate $c a .90 \%$ smaller than other primate species capable of dispersing comparably high numbers

Fig. 6 Determination of the most suitable conditions for the dispersal of nonpioneer species seeds in secondary forest: correlation between $\%$ of nonpioneer species seeds dispersed in secondary forest and mean duration of entries (a), polynomial regression of mean duration of entries with the frequency of entries (b), and polynomial regression of the secondary-forest-to-primary-forest ratio of time eating fruits (EF sf/EF pf) with the frequency of entries in secondary forest (c). 
(A)

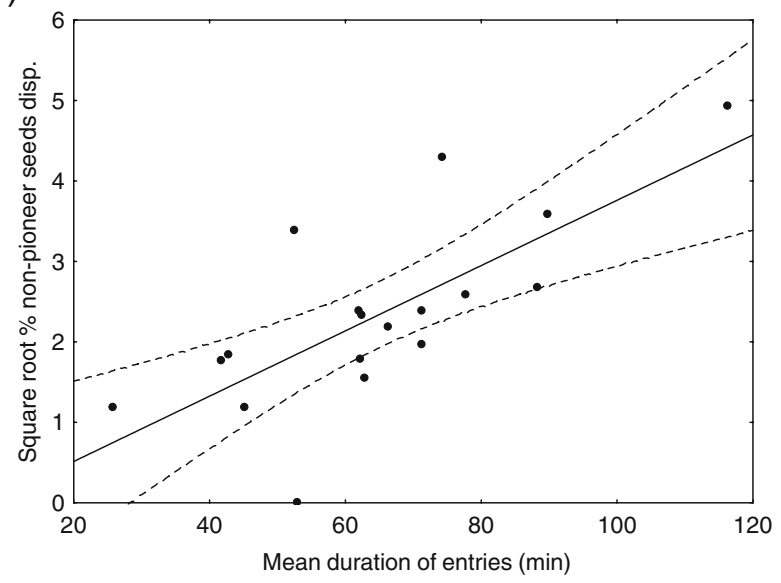

(B)
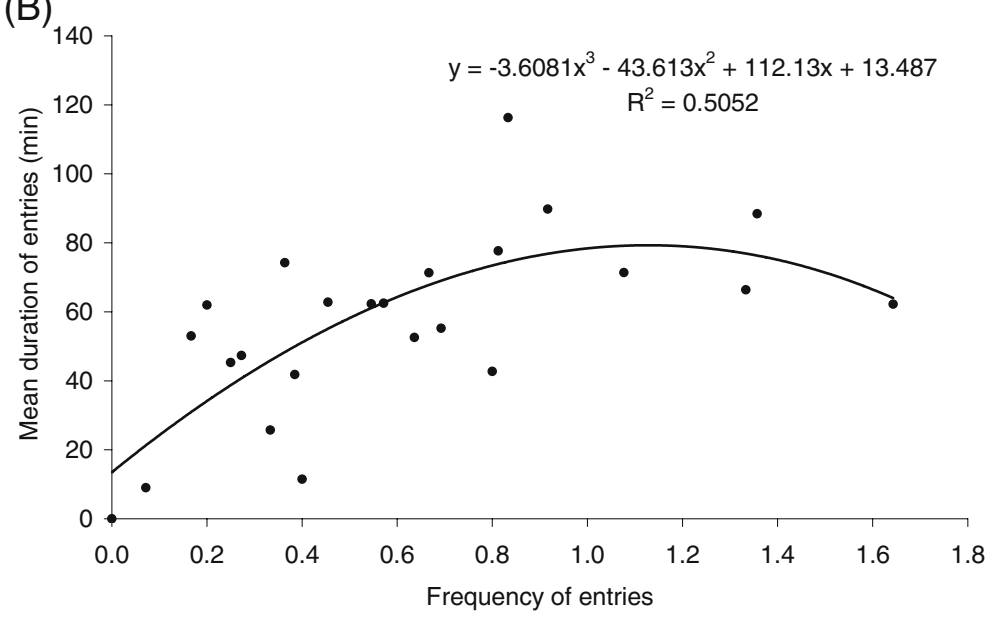

(C)

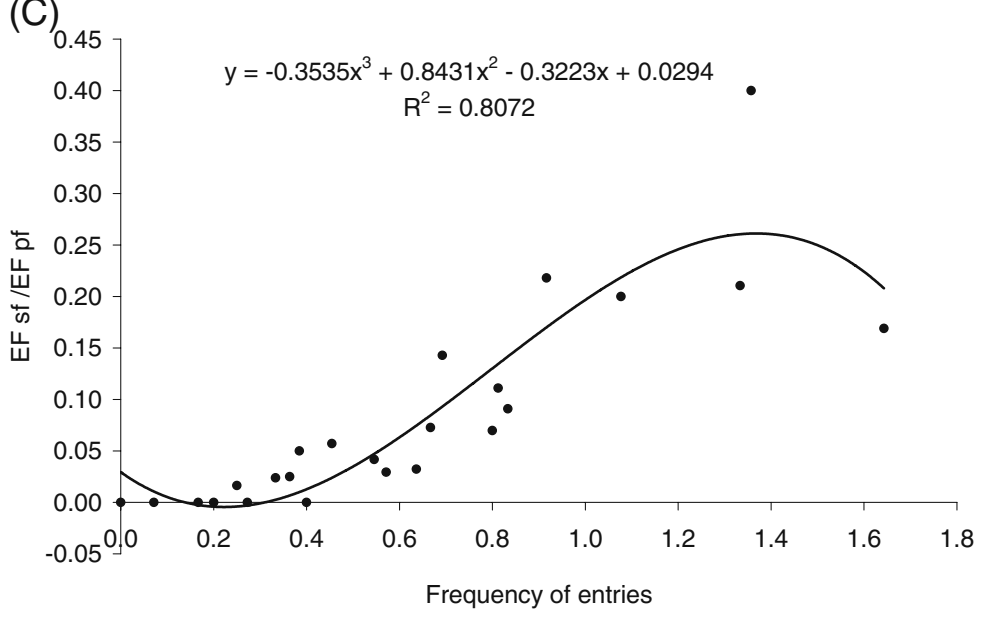


of plant species: Alouatta seniculus L. (Andresen 2002), Lagothrix lagothricha Humb. (Stevenson 2000). We thus state that even small primate species such as tamarins can play a significant role in forest regeneration, which has been largely neglected until now. Moreover, tamarins disperse many plant species commonly used by humans for construction, medicine, or food (Pacheco Gómez et al. 1998).

\section{Seasonality and Seed Rain in Secondary Forest}

The effect of seasonality on home range use and diet was reflected in the composition and the spatial structure of seed rain. As Dosch et al. (2007) observed, the density and composition of seeds dispersed vary throughout the year and did the proportion of pioneer and nonpioneer seeds. As a large part of the seeds dispersed by tamarins in secondary forest were $>1 \mathrm{~cm}$ and large seeds are generally late successional (Foster and Janson 1985; Leishman et al. 2000), an increase of seed arrival in secondary forest suggests that diversity may increase not only in species but also in functional groups.

Duration of entries predicted the proportion of nonpioneer seeds (and thus mainly large seeds) dispersed in secondary forest best. The optimum period for the dispersal of species involved in later stages of forest regeneration corresponded to the late wet season in our study site. During that period, frequency of entries in secondary forest were intermediate and dietary diversity was high but a nonnegligible part consisted of pioneer species. This was confirmed by the fact that the time periods tamarins spent eating fruits in secondary and primary forest were more equal. Long-lasting incursions of the late wet season were associated with a higher overall proportion of seeds dispersed in secondary forest than during the dry season. The probability of defecation increased as the tamarins spent more time continuously in secondary forest. Likewise, a higher dietary diversity during the late wet season allowed the dispersion of a higher proportion of nonpioneer species seeds than during the other seasons, even though a proportion of fruits from pioneer trees in the secondary forest was still used. In this manner, in the late wet season, tamarins increased the probability of their dispersing nonpioneer seeds from primary to secondary forest by $11.4 \%$ compared to the early wet season.

Our results suggest that, even if nonpioneer species seeds from primary forest were dispersed in secondary forest year-round, the seasonal variation in the intensity of use of the latter area implied an unequal potential contribution to forest regeneration among the plant species dispersed by tamarins. However, the seasonal variation of seed rain induced by tamarins might benefit the plants, as from their perspective recruitment trajectories may change over time if seed rain changes (Harms et al. 2000), potentially increasing the odds of altering successional stages and diversity in the regeneration process.

Our study showed that, during the time tamarins spent eating fruits in the nearby primary forest, the actual seed source (Laborde et al. 2008) was of paramount importance for forest regeneration. Similarly, in a study using artificial perches to attract seed dispersers, more seeds were deposited under perches when fruit production in the nearby vegetation increased (Zanini and Ganada 2005). Fruit production in the secondary forest highly influences both frequency and duration of visits, as well as the seed shadow. As also shown in our study by the concentration 
of seeds under patches of pioneer fruiting trees (essentially Cecropia and Bellucia pentamera trees), remnant trees were essential to attract seed dispersers and hence to initiate seed colonization (Da Silva et al. 1996; Hooper et al. 2005; Parrotta et al. 1997). Indeed, these recruitment foci initiate the nucleation process by the formation of tree islands that gradually expand and coalesce (Slocum 2001). Finally, in the later stages of succession, the structural complexity of the vegetation is also important, as, for instance, tamarins will also look for foraging or resting sites while entering secondary forest.

\section{Conclusions}

The high diversity of seed species of different life forms consumed by these two small primate species, their capacity to disperse a high diversity of nonpioneer species seeds and to use young secondary forest indicates their importance for the maintenance of plant diversity and forest regeneration. The seed shadow produced by tamarins can be explained by their behavior. For instance, the duration of entries and distances traveled in degraded areas are factors to take into account in any attempt to determine the effectiveness of seed dispersers in the forest regeneration process. The seasonality of seed dispersal is another factor of paramount importance, as the temporal variation of seed rain might affect the recruitment and hence the plant community structure by modifying the plant species involved in the competition for seedling emergence and survival. In degraded areas, this variability might be strengthened through the dependency of seed dispersers on phenology of the secondary forest but also of the surrounding primary forest. Considering the high variability in species responses (Johns and Skorupa 1987) and year-to-year variations in phenology (Chapman and Chapman 2002), we recommend long-term studies of the behaviors of other seed dispersers across different years to adapt management and conservation plans to specificities of seed disperser communities and habitats.

\footnotetext{
Acknowledgments We thank N. Cordeiro, N. Farwig, V. Lehouck, and 2 anonymous reviewers for very helpful discussions and comments on the manuscript as well as Joy Schochet for English language revision. We thank our field assistant, Jeisen Shahuano Tello, for his help on the field and Ricardo Zárate and Carlos Amasifuen for the identification of plant species and forest characterization. This study was made possible by a grant from FRIA (Fonds pour la formation à la recherche dans l'industrie et dans l'agriculture) and FNRS (Fonds National de la Recherche Scientifique), Belgium, to Laurence Culot. We thank INRENA (Peru) for permission to conduct research at the Estación Biológica Quebrada Blanco (authorizations 011-2005-INRENA-IFFS-DCB，071-2005-INRENA-IFFS-DCB，059-2006-INRENAIFFS-DCB and 114-2007-INRENA-IFFS-DCB).
}

Open Access This article is distributed under the terms of the Creative Commons Attribution Noncommercial License which permits any noncommercial use, distribution, and reproduction in any medium, provided the original author(s) and source are credited.

\section{References}

Andresen, E. (2002). Primary seed dispersal by red howler monkeys and the effect of defecation patterns on the fate of dispersed seeds. Biotropica, 34, 261-272. 
Chapman, C. A. (1995). Primate seed dispersal: coevolution and conservation implications. Evolutionary Anthropology, 4, 74-82.

Chapman, C. A., \& Chapman, L. J. (1999). Forest restoration in abandoned agricultural land: a case study from East Africa. Conservation Biology, 13, 1301-1311.

Chapman, C. A., \& Chapman, L. J. (2002). Plant-animal coevolution: is it thwarted by spatial and temporal variation in animal foraging? In D. J. Levey, W. R. Silva, \& M. Galetti (Eds.), Seed dispersal and frugivory: Ecology, evolution and conservation (pp. 275-290). Wallingford: CABI.

Chapman, C. A., \& Russo, S. E. (2006). Primate seed dispersal: linking behavioral ecology with forest community structure. In C. J. Campbell, A. Fuentes, K. C. MacKinnon, M. Panger, \& K. Bearder (Eds.), Primates in perspective (pp. 510-525). Oxford: Oxford University Press.

Da Silva, J. M. C., Uhl, C., \& Murray, G. (1996). Plant succession, landscape management, and the ecology of frugivorous birds in abandoned Amazonian pastures. Conservation Biology, 10, 491-503.

Dosch, J. J., Peterson, C. J., \& Haines, B. L. (2007). Seed rain during initial colonization of abandoned pastures in the premontane wet forest zone of southern Costa Rica. Journal of Tropical Ecology, 23, 151-159.

Foster, S. A., \& Janson, C. H. (1985). The relationship between seed size and establishment conditions in tropical woody plants. Ecology, 66, 773-780.

Furuichi, T., Hashimoto, C., \& Tashiro, Y. (2001). Fruit availability and habitat use by chimpanzees in the Kalinzu forest, Uganda: examination of fallback foods. International Journal of Primatology, 22, 929-945.

Garber, P. A. (1988). Diet, foraging patterns, and resources defense in a mixed species troop of Saguinus mystax and Saguinus fuscicollis in Amazonian Peru. Behaviour, 105, 18-34.

Garber, P. A. (1993). Seasonal patterns of diet and ranging in two species of tamarin monkeys: stability versus variability. International Journal of Primatology, 14, 145-166.

Gentry, A. H. (1988). Tree species richness of upper Amazonian Forests. Proceedings of the National Academy of Sciences of the United States of America, 85, 156-159.

Gorchov, D. L., Cornejo, F., Ascorra, C., \& Jaramillo, M. (1993). The role of seed dispersal in the natural regeneration of rain forest after strip-cutting in the Peruvian Amazon. Vegetatio, 107(108), 339-349.

Harms, K. E., Wright, S. J., Calderón, O., Hernández, A., \& Allen Herre, E. (2000). Pervasive densitydependent recruitment enhances seedling diversity in a tropical forest. Nature, 404, 493-495.

Hemingway, C. A., \& Bynum, N. (2005). The influence of seasonality on primate diet and ranging. In D. K. Brockman \& C. P. Van Schaik (Eds.), Seasonality in primates (pp. 57-104). Cambridge: Cambridge University Press.

Heymann, E. W. (1990). Interspecific relations in a mixed-species troop of moustached tamarins, Saguinus mystax, and saddle-back tamarins, Saguinus fuscicollis (Platyrrhini:Callitrichidae), at the Rio Blanco, Peruvian Amazonia. American Journal of Primatology, 21, 115-127.

Hill, R. (2005). Day length seasonality and the thermal environment. In D. K. Brockman \& C. P. Van Schaik (Eds.), Seasonality in primates (pp. 197-213). Cambridge: Cambridge University Press.

Holl, K. D. (1999). Factors limiting tropical rainforest regeneration in abandoned pasture: seed rain, seed germination, microclimate, and soil. Biotropica, 31, 229-242.

Hooper, E., Legendre, P., \& Condit, R. (2005). Barriers to forest regeneration of deforested and abandoned land in Panama. Journal of Applied Ecology, 42, 1165-1174.

Johns, A. D., \& Skorupa, J. P. (1987). Responses of rain-forest primates to habitat disturbance: a review. International Journal of Primatology, 8, 157-191.

Knogge, C., \& Heymann, E. W. (2003). Seed dispersal by sympatric tamarins, Saguinus mystax and Saguinus fuscicollis: diversity and characteristics of plant species. Folia Primatologica, 74, 33-47.

Laborde, J., Guevara, S., \& Sánchez-Ríos, G. (2008). Tree and shrub seed dispersal in pastures: the importance of rainforest tree outside forest fragments. Ecoscience, 15, 6-16.

Leishman, M., Wright, I., Moles, A., \& Westoby, M. (2000). The evolutionary ecology of seed size. In M. Fenner (Ed.), Seeds: The ecology of regeneration in plant communities (pp. 31-57). Wallingford: CABI.

Liebsch, D., Marques, M. C. M., \& Goldenberg, R. (2008). How long does the Atlantic rainforest take to recover after a disturbance? Changes in species composition and ecological features during secondary succession. Biological Conservation, 141, 1717-1725.

Martin, P. R., \& Bateson, P. P. G. (1993). Measuring behaviour: An introductory guide (2nd ed.). Cambridge: Cambridge University Press.

Martínez-Garza, C., \& Howe, H. F. (2003). Restoring tropical diversity: beating the time tax on species loss. Journal of Applied Ecology, 40, 423-429.

Medellín, R. A., \& Gaona, O. (1999). Seed dispersal by bats and birds in forest and disturbed habitats of Chiapas, México. Biotropica, 31, 478-485.

Moegenburg, S. M., \& Levey, D. J. (2003). Do frugivore respond to fruit harvest? An experimental study of short-term responses. Ecology, 84, 2600-2612. 
Oliveira, A. C. M., \& Ferrari, S. F. (2000). Seed dispersal by black-handed tamarins, Saguinus midas niger (Callitrichinae, Primates): implications for the regeneration of degraded forest habitats in eastern Amazonia. Journal of Tropical Ecology, 16, 709-716.

Olupot, W., Chapman, C. A., Waser, P. M., \& Isabirye-Basuta, G. (1997). Mangabey (Cercocebus albigena) ranging patterns in relation to fruit availability and the risk of parasite infection in Kibale National Park, Uganda. American Journal of Primatology, 43, 65-78.

Pacheco Gómez, T., Burga Alvarado, R., Angulo Ruiz, P. A., \& Torres Vásquez, J. (1998). Capítulo 9: Evaluación de bosques secundarios de la zona de Iquitos. In R. Kalliola \& S. Flores Paitán (Eds.), Geoecología y desarrollo Amazónico: Estudio integrado en la zona de Iquitos, Perú, vol, 114 (pp. 389-416). Sulkava, Finland: Turun Yliopiston Julkaisuja.

Parrotta, J. A., Knowles, O. H., \& Wunderle, J. M., Jr. (1997). Development of floristic diversity in 10-year-old restoration forests on a bauxite mined site in Amazonia. Forest Ecology and Management, 99, 21-42.

Peres, C. A. (1993). Diet and feeding ecology of saddle-back (Saguinus fuscicollis) and moustached ( $S$. mystax) tamarins in an Amazonian terra firme forest. Journal of Zoology, 230, 567-592.

Rodgers, A. R., \& Carr, A. P. (1998). HRE: The home range extension for Arcview ${ }^{T M}$ : User's manual. Ontario Ministry of Natural Resources, Centre for Northern Forest Ecosystem Research Ontario. URL: http://blue.lakeheadu.ca/hre/ (access year: 2006).

Ruokolainen, K., \& Tuomisto, H. (1998). Capítulo 7: Vegetación natural de la zona de Iquitos. In R. Kalliola \& S. Flores Paitán (Eds.), Geoecología y desarrollo Amazónico: Estudio integrado en la zona de Iquitos, Perú, vol. 114 (pp. 253-365). Sulkava, Finland: Turun Yliopiston Julkaisuja.

Russo, S. E., Portnoy, S., \& Augspurger, C. K. (2006). Incorporating animal behavior into seed dispersal models: implications for seed shadows. Ecology, 87, 3160-3174.

Slocum, M. G. (2001). How tree species differ as recruitment foci in a tropical pasture. Ecology, 82, 25472559.

Smith, A. C. (2000). Composition and proposed nutritional importance of exudates eaten by saddleback (Saguinus fuscicollis) and mustached (Saguinus mystax) tamarins. International Journal of Primatology, 21, 69-83.

Soini, P., \& Coppula, M. (1981). Ecología y dinámica poblacional de pichico Saguinus fuscicollis (Primates, Callitrichidae). Informe de Pacaya, 4, 1-43.

Soini, P., \& Soini, M. (1982). Distribución geográfica y ecología poblacional de Saguinus mystax (Primates, Callitrichidae). Informe de Pacaya, 6, 1-56.

Stevenson, P. R. (2000). Seed dispersal by woolly monkeys (Lagothrix lagothricha) at Tinigua National Park, Colombia: dispersal distance, germination rates, and dispersal quantity. American Journal of Primatology, 50, 275-289.

Stoner, K. E., Riba-Hernandez, P., Vulinec, K., \& Lambert, J. E. (2007). The role of mammals in creating and modifying seed shadows in tropical forests and some consequences of their elimination. Biotropica, 39, 316-327.

Uhl, C., Buschbacher, R., \& Serrão, E. A. S. (1988). Abandoned pastures in eastern Amazonia: I. Patterns of plant succession. Journal of Ecology, 76, 663-681.

Van Schaik, C. P., Terborgh, J. W., \& Wright, S. J. (1993). The phenology of tropical forest: adaptive significance and consequences for primary consumers. Annual Review of Ecology and Systematics, 24, 353-377.

Vulinec, K., Lambert, J. E., \& Mellow, D. J. (2006). Primate and dung beetle communities in secondary growth rain forests: implications for conservation of seed dispersal systems. International Journal of Primatology, 27, 855-879.

Webb, C. O., \& Peart, D. R. (2001). High seed dispersal rates in faunally intact tropical rain forest: theoretical and conservation implications. Ecology Letters, 4, 491-499.

Wunderle, J. M., Jr. (1997). The role of animal seed dispersal in accelerating native forest regeneration on degraded tropical lands. Forest Ecology and Management, 99, 223-235.

Zanini, L., \& Ganada, G. (2005). Restoration of Araucaria forest: the role of perches, pioneer vegetation, and soil fertility. Restoration Ecology, 13, 507-514. 